The Private Governance of Food: Equitable Exchange or Bizarre Bazaar?

\author{
Lawrence Busch \\ Institute for Food and Agricultural Standards \\ Michigan State University \\ East Lansing, MI 48824 \\ USA \\ Paper presented a symposium on the Private Governance in the Global Agro-Food \\ System, Münster, Germany, April 2008.

\begin{abstract}
In recent years, we have witnessed three parallel and intertwined trends: First, food retail and processing firms have embraced private standards, usually with some form of third party certification employed to verify adherence to those standards. Second, firms have aligned themselves increasingly aligned themselves with, as opposed to fighting off, environmental, fair trade, and other NGOs. Third, firms have embraced supply chain management as a strategy for increasing profits and market share. Together, these trends are part and parcel of the neoliberal blurring of the older liberal distinction between state and civil society. In this paper I ask what the implications of these changes are from the vantage point of the three major approaches to ethics: consequentalism, virtue theory, and rights theory. What are the consequences of these changes for food safety, for suppliers, for consumers? What virtues (e.g., trust, fairness) are these changes likely to embrace and what vices may accompany them? Whose rights will be furthered or curtailed by these changes?
\end{abstract}




\title{
The Private Governance of Food: Equitable Exchange or Bizarre Bazaar?
}

\author{
Lawrence Busch \\ Institute for Food and Agricultural Standards \\ Michigan State University
}

\section{Introduction}

In recent years, we have witnessed three parallel and intertwined trends: First, food retail and processing firms have embraced private standards, usually with some form of third party certification employed to verify adherence to those standards. For example, many supermarket chains have joined GlobalGAP (2008) (previously known as EurepGAP), an association designed to create and implement common private food safety, environmental, and worker health and safety standards among its members. Farms must engage an approved third party certifier to audit for compliance to the standards. Similarly, CIES (2002) has established a Global Food Safety Initiative in an attempt to create a common benchmark for food safety globally.

Second, firms have increasingly aligned themselves with, as opposed to fighting off, environmental, fair trade, and other NGOs. Put differently, firms have begun to understand that NGOs are the new superbrands, able to mobilize a small but highly influential segment of the public that is strongly concerned about farm worker health and safety, animal welfare, environmental degradation, local sourcing, organic production, or some other issue (Wootliff and Deri 2001). Given the rather low profit margins in both food processing and retailing, firms can ill afford the adverse publicity associated with NGO campaigns. In contrast, they are happy to have the support - and free advertising that NGOs can bring them.

Third, firms have embraced supply chain management as a strategy for increasing profits and market share. Until about twenty years ago, food processing and especially food retailing was a rather inefficient sector of the economy. Food processors depended on consumer recognition of their brand names, while retailers purchased whatever processors concocted, bringing it in through the back door and moving it out through the front door. Initially, given the small size of most retailers and the much larger size and visibility of the processors, retailers had little choice. But even after the creation of the first wave of large supermarket chains, the business model remained largely unchanged.

This all shifted with the creation of a new wave of retailers who were determined to reorganize the retail business so as to increase its profitability. The watchword for food retailing became 'efficient consumer response,' an approach that emphasized adapting techniques developed in manufacturing to food retailing (Brown 1997; Caswell, Bredahl and Hooker 1998). Hence, companies such as Wal-Mart, Carrefour, and Aldi began to shift from individual store management to supply chain management. Put differently, executives at these chains began to see that they were sufficiently large that they could think of their stores as the end of a long and complex pipeline through which many goods might flow and act accordingly. Moreover, they could dominate those supply chains, 
dictating to suppliers a variety of quality characteristics of food products, timing of deliveries, and stocking of shelves. Indeed, they could coordinate vertically such that package size and shape, brand labels, organoleptic qualities, and supplier business models were all influenced or even controlled by the supermarkets (Busch 2007)

Together, these trends are part and parcel of the neoliberal blurring of the older liberal distinction between state and civil society (Friedman 1962; Hayek 1973; 1976; 1979). In their quest to limit the power of the nation-state proponents of neoliberalism have worked hard for more than a half century to reduce state regulation of markets, create international institutions that limit state power, and whenever possible employ markets as distributive systems. In so doing, they have opened the door to the creation of private governance systems such as those described here. ${ }^{1}$

State power is backed up by state sanctions, e.g., violation of food safety laws may be punishable by payment of a fine, time in prison, and/or forced closure of a business. In contrast, private power is backed up by market sanctions, e.g., removal from a given market. Hence, the shift from government to governance is best understood as (1) an enhancement of the ability of certain firms to dominate supply chains, reducing costs by imposing a new form of discipline on other (usually upstream) firms in the chain, and (2) the realization by NGOs of their potential to pressure the dominant firms.

In this paper I ask what the ethical implications of these changes are. In representative democracies the state is the final arbiter of many critical moral and ethical issues.

Elected legislative bodies are charged with creating uniform laws that are to be uniformly enforced across some defined territory. Clearly, critics of state power rightly argue that (even democratic) states can be quite oppressive in their actions (Constant 1988; Scott 1998). Yet, as this paper attempts to make clear, private governance structures pose an analogous, and perhaps more intractable, set of problems.

A central feature of private governance is an expanded role for the market. The modern market ${ }^{2}$ is, virtually by definition, based on a particular interpretation of commutative justice. The principle of commutative justice asserts that, if the parties are uncoerced, there is an equivalence between two articles exchanged; hence, the exchange is said to be just. From this was derived the medieval term 'just price,' which referred to a price fixed by a third party as fair and just based on the labor required to produce a given item. However, in modern markets, that equivalence is based on the so-called laws of supply and demand, or in other words, scarcity is explicitly included in the calculation. Thus, equivalence is presumed to exist when a monetary exchange takes place; the power relationship - what Samuels (2004) calls a 'structure of mutual coercion' - often found in the market is excluded from the analysis (or at least from the view of the some economists and often from the view of participants).

\footnotetext{
${ }^{1}$ Curiously, it appears that the major proponents of neoliberalism did not foresee the rise of private governance institutions, including standards, certifications, and accreditations.

${ }^{2}$ E. P. Thompson $(1963 ; 1971)$ noted some years ago that pre-modern markets developed in the context of a moral economy, i.e., a means for grappling with issues of distributive justice. The creation of capitalist markets involved a long struggle to eliminate these distributive mechanisms.
} 
Yet, as Ayres suggests,

It simply is not true that scarce resources are allocated among alternative uses by the market. The real determinant of whatever allocation occurs in any society is the organizational structure of that society - in short, its institutions. At most, the market only gives effect to prevailing institutions (quoted in Samuels 2004, 364).

It is precisely because mainstream economics largely avoids discussion of how markets come to be structured in particular ways that concerns about equitable exchange have arisen.

This suggests, in turn, that there are two conceptually different critiques of private systems of governance. The first emerges from a concern that commutative justice is not obtained through existing markets because of the unequal power of the participants to alter the structure of the exchange. The second, and more profound critique, argues that attention paid to commutative justice to the exclusion of distributive justice is unacceptable. The former argument suggests tinkering with the structure of the marketplace, but accepts the notion that the market is the proper mechanism for handling the problem posed. The latter position argues that other non-market institutions must intervene to satisfactorily resolve the problem posed.

\section{Ethical Dilemmas}

Philosophers generally acknowledge three major approaches to ethics: consequentalism, virtue theory, and rights theory. While purists may insist that one approach is invariably better than the others for the resolution of all ethical problems, I make no such claim here. In fact, quite to the contrary, I argue that each approach asks a different set of questions and thereby reveals a different aspect of the issues at hand. Hence, from a consequentialist perspective one may ask: What are the consequences of these changes for food safety, for consumers, and for suppliers? From a virtue ethics perspective one may ask: What virtues (e.g., trust, fairness) are these changes likely to embrace and what vices may accompany them? And, finally, from the perspective of rights theory one may ask: Whose rights will be furthered or curtailed by these changes? While space does not permit a thorough examination of all of these issues, let us examine several of each in turn.

\section{Consequences}

Multiple tiers of safety. We take for granted when we enter any shop that goods will vary in price and qualities. If I wish to buy chocolate, I may buy a very cheap type containing relatively little cocoa, or an expensive type containing mostly cocoa. Prices are likely to vary accordingly. The same will apply for virtually any food product I buy. In contrast, when I purchase a food product at any supermarket in any industrialized nation, I am confident that it has quite likely passed all the necessary tests of safety. This was not 
always the case. As Stanziani (2005) has noted, prior to the late nineteenth century, food safety was in the hands of the buyer. Caveat emptor was the order of the day.

But the shift to private governance of food raises the possibility of a shift in food safety from a single standard to one that has multiple tiers, e.g., barely safe, safe enough, very safe. Under such a system of governance, food safety would become a matter of market affordability rather than of general protection of the public by the state. Indeed, unwittingly, and perhaps only temporarily, the Chinese system for food safety is already a three tier system with organic food, 'green food' (certified as using agrochemicals within safe limits), and everything else. While the Chinese appear to see this as a temporary measure, on the way to a single uniform standard of safety, it could easily evolve into a permanent three tier system.

Moreover, in a somewhat paradoxical manner, the recent efforts on the part of CIES (2002) to develop a single, global benchmark for food safety, may actually encourage the creation of multiple tiers. On the one hand, CIES's actions are clearly raising the bar on food safety, since the benchmarked standards appear to satisfy the food safety agencies of numerous nations. On the other hand, such benchmarking is not cost-free and might well spur the creation of another, weaker standard.

For consumers. Consequences for (many) consumers may actually be quite positive. Worldwide, the presence of supermarkets is growing, and they are no longer reserved for the wealthy and middle classes (Dries, Reardon and Swinnen 2004; Reardon et al. 2003; Weatherspoon and Reardon 2003). Indeed, because supermarkets can reorganize supply chains, and because they often operate under conditions of acute competition among themselves, supermarkets can and do offer consumers lower prices, better quality, greater variety, and safer food than they might have purchased in open-air wet markets or small family-owned grocery stores. However, consumers may find that they need to travel further to purchase food. Furthermore, supermarkets may promote foods that are higher in fat and sugar than traditional diets, thereby contributing to the worldwide concerns about obesity.

For suppliers including farmers and farm workers. The private governance of food poses several major although largely unintended consequences for farmers and farm workers. Let us first examine the situation for farmers. On the one hand, farmers who are able to become certified to supermarket standards are likely to find themselves in long term relations with buyers. This may result in lower prices for goods sold in some years, but it will likely also result in more stable prices as farmers will be able to put far more of their production under contract (Busch et al. 2005). At the same time, however, such farmers will find themselves in direct competition with other farmers growing the same crops or livestock in other parts of the world. Farmers' only means of protecting themselves from this will be through the continuous development of new niche markets for particular products (e.g., new varieties of fruit), or by taking advantage of the seasonality of production. ${ }^{3}$

\footnotetext{
${ }^{3}$ Chile has built its entire fruit industry on this counterseasonal production.
} 
On the other hand, farmers who - for whatever reason - fail to meet supermarket standards will likely be forced into a declining market segment in which prices received are lower, markets are more volatile, and quality premiums are extremely variable. Likely, many of these farmers will move to the ever-burgeoning cities where they will add to urban slums.

For farm workers the situation is likely to be far more serious, but equally bifurcated. Given the downward pricing pressure put on farmers by supermarkets - either directly through contracts, or indirectly through farmer competition - all farmers are likely to press for low wages and/or replace farm workers with machinery. Beyond that, it appears that a two tier system is developing whereby provisions for full time workers are reasonably good as a result of certification requirements - this would include a variety of things from protective clothing for use in spraying pesticides, to provision of toilets and cafeterias - while part time and temporary workers are poorly paid and exposed to pesticides - (see, for example, Bain 2007).

That said, I see no reason to make the world safe for poverty. A decline in the number of persons on small farms, and a similar decline in the number of farm workers is far more problematic if they wind up unemployed in the slums, bidonvilles, barrios, than if they find jobs elsewhere in the economy at higher wages. Unfortunately, this rarely happens; instead slum populations are growing faster than the general population and now include more than one billion people (United Nations Human Settlement Programme 2003).

\section{Virtues}

Trust. Perhaps the key virtue that is transformed by the restructuring of the food system is trust. We may consider trust as consisting of two interrelated parts (Beekman 2004). First, there is trust in persons. This sort of trust, which must at least initially be displayed in face to face settings, is dialogical. This dialogue includes exchange of words, but it is also an exchange of gestures (Mead 1962), and of things (Latour 1987). Moreover, as Goffman (1993) has suggested, face is also dialogical.

Consider how this plays out in everyday life. Those persons around me are trusted to varying degrees based on my experiences with them. Someone who appears trustworthy is someone on whom I can rely. For example, I may trust the local butcher to provide me with cuts of meat that meet my desires. But he may also trust me, by offering to sell on credit, trusting that I will indeed pay the debt within a reasonable period of time. Importantly, this form of trust goes far beyond dependability; it includes the ability to extend trust to new kinds of relationships.

But our everyday understanding of trust goes yet further, incorporating our relationships with things. This is certainly true of simple tools which we come to know as our own to such a degree that they become extensions of our bodies (Idhe 1979; Idhe 1990). Dental tools and hammers are excellent examples of this kind of trust. Nor does it stop there. Automobiles become extensions of one's body, such that an experienced driver knows when the actions of a vehicle are 'abnormal.' These relations, although far less rich than 
those with fellow humans, are also dialogical. We come to communicate with and through these objects. We come to 'know' these objects as having certain properties, and performing faithfully certain actions. But, unlike the trust we place in other humans, trust in objects is generally understood solely as dependability. ${ }^{4}$ Nevertheless, dialogue, I submit, is essential to both of these everyday understandings of trust.

In contrast, the trust that is created through conformity assessment is quite different in that it is essentially monological. Indeed, some would not call it trust at all, but rather a poor substitute for it. In each instance, the person or thing that is certified to meet a given set of standards that appears to us as largely opaque. We are typically confronted by a logo, a seal, a certificate, that proclaims conformity to some (often hidden and sometimes secret) set of standards. We are normally neither a party to the determination of those standards, nor do we know the details of the contents of the standards, nor are we party to the certification of a person or thing to those standards, or to the accreditation of the certifying body. And, we must either blindly trust in the logo or seal (and what appears to stand behind it) or flatly reject it.

Importantly, even if we trust the certified person or object in this limited monological sense, we must later convert it - through experience - into dialogical trust. But this is not a matter of learning what the standards are, how the certification was conducted, or how the accreditation agency works. It is a matter of converting, translating, reshaping the monological trust in the logo into personal experience and dialogue with the certified person or thing. Put differently, even operating in its most effective manner, the trust that emerges out of conformity assessment is and must be impoverished. As such, living in a world in which all forms of trust are monological would be nearly intolerable as it would replace the richness of dialogue and experience with a focus on the surface characteristics.

Fairness. Fairness is commonly claimed by proponents of certain certifications (e.g., fair-trade certifications). But, as with trust, claims to fairness are and must remain problematic for many of the same reasons. In everyday situations fairness is something that we claim or deny for particular situations. We note that certain exchanges are unfair, while others are fair. But in the case of fair-trade and like certifications, we must accept the decision made by some unknown person or persons as to the fairness of the exchange that is likely made somewhere far removed from where we are. This is not to suggest that the persons determining that an exchange is fair are in any way attempting either to force their views on us or to conceal what are in fact unfair practices. Rather, we are likely unfamiliar with the formal criteria employed, nor do we fully understand how they are employed. We must accept on faith that those doing the certifying have an understanding of fairness that is similar to our own.

Doubtless, other virtues such as honesty and integrity are displayed differently in systems of private governance. But I shall leave to others the task of examining those differences. Let us now turn to rights.

\footnotetext{
${ }^{4}$ Beekman (2004) argues that humans may also be trusted in this way, where trust is viewed as consistent but not necessarily desirable - behavior.
} 


\section{Rights}

To manage one's own affairs. Conformity assessments can and often do challenge the rights of persons to manage their own affairs. Consider a 1905 contract for the production of tomatoes in New Jersey, reproduced in its entirety:

This is to certify that we have bought of the product of acres of tomatoes for the season of at $\$$ per ton, delivered at our cannery at Stock to be in first-class mercantile condition, To be planted about (Corbett 1905).

To readers a century later, it is astonishing for what it does not include. Similar contracts today would not only specify just what is meant by 'first-class mercantile condition;' they would likely also include one or more certifications. These certifications would focus on myriad other details about planting, spacing, farm worker housing conditions, availability of toilets, use of pesticides and other farm chemicals, etc. Thus, one aspect of certifications is that they often impose considerable constraints on the actions of upstream actors. (GlobalGAP has a wide range of major and minor musts. Growers are required to meet $100 \%$ of the major musts and $95 \%$ of the minor musts.) And, while it is true that certifications are voluntary, they are often de facto mandatory. Nor is the problem limited to standards promulgated by companies. NGOs, despite having often the very best of intentions, may make equally strong demands on upstream actors (Gereffi, Garcia-Johnson and Sasser 2001).

To Redress of Grievances. Moreover, of particular concern is that these new forms of private governance rarely if ever have anything even vaguely resembling an appeals process or a separation of powers. In general, once one fails to comply with the standards, as evidenced by failure to become or remain certified, there is little that one can do about it. And, even if appeals are permitted, they are usually appeals to the same persons or organizations that rejected the action in the first place. An analogy would be an appeal by a serf to a medieval lord over the lord's actions. Of course, it might be argued that the serf was bound to the land and hence could not go elsewhere. However, while in principle supply chain linkages are voluntary, they are often de facto mandatory, either in the sense that no other options exist or that other options involve considerable losses.

The right to choose. It would seem that the new system of private governance enhances consumers' right to choose. After all, it creates markets in which there is a seemingly endless array of products, both fresh and processed. In the supermarket in my hometown, I can now buy certified fair trade coffee, free range eggs, organic carrots, and sustainably harvested fish. I am confident that I will soon be able to choose foods that minimize carbon emissions. And, I can choose among foods produced in dozens of nations. Nor is this unique to the industrial world. In China, India, Kenya, Guatemala one sees a similar growth in the diversity of products found on the shelves. Without a doubt, the range of food choices available to many people has grown exponentially in the last 
several decades and it appears to continue to expand. But at the same time, the drive to private governance tends to turn choice into a burden. Consider that, in addition to price and quality considerations, coffee may be certified for organic, fair trade, bird friendly, shade grown, protective of biodiversity, region of origin, and/or kosher! Which, if any, of these certifications should I choose? Can any consumer be expected to make the myriad ethical and moral choices now demanded in the supermarket? Empirical evidence and personal experience suggest that, since shoppers are nearly always pressed for time, they tend to buy those items with which they are most familiar and that few if any consumers ponder the information on the labels of all the products they purchase.

In sum, private governance of food poses a number of ethical issues, regardless of the ethical perspective one takes on it. So what can we conclude?

\section{Conclusions: Equitable Exchange or Bizarre Bazaar?}

One may argue that state intervention in the form of law shares many of the problems described above. However, let me suggest that legal frameworks differ from conformity assessment in at least three important ways: First, legal frameworks are homogeneous across some defined area of territory. In general, one does not choose which laws to follow, or when to follow them. In contrast, it is commonplace to have multiple systems of conformity assessment, some of which overlap and others of which are contradictory.

Second, laws (with a few exceptions) remain valid only within national borders. In contrast, certifications commonly extend far beyond national borders; hence, downstream expectations may well conflict with expectations upstream. For example, Hatanaka (2006) found that shrimp farmers in one region of Indonesia found organic certification requirements imposed by foreign buyers to be problematic in several respects, given local knowledge and conditions.

Third, laws often provide severe sanctions for violations, but they are very rarely specified at the level of detail as are conformity assessments. Hence, laws provide multiple ways of achieving (or avoiding) the same results. Paradoxically, although laws provide no escape clause from state sanctions, certifications are often more restrictive of personal liberties.

This brings us back to the two very different critiques of private systems of governance. Nearly all NGO-led interventions into such governance systems are focused on rectifying what is perceived as the unequal power of the participants in the exchange relationship. This is certainly the case for NGOs concerned about the treatment of farmers and farm workers. There are many examples of success in these endeavors. For example, a recent analysis concluded that fair trade now accounts for $€ 1000$ million per annum (Eyre 2008). The same may be said about those NGOs concerned about other non-human actors such as forests, fish, animals, and 'the environment.' In contrast, relatively few NGOs have adhered to the more profound critique, demanding a reworking of the institutions that govern trade such that issues of distributive justice are taken more seriously as well as demanding more state intervention in the form of new laws. 
In short, the reader looking for a simple answer to this question will be disappointed by my conclusions. For while the private governance of food permits and even stimulates some forms of (more) equitable exchange, it also creates a bizarre bazaar where goods are differentiated by a growing and often bewildering array of criteria, most of which are only made visible to consumers through certifications. This dual process simultaneously (1) addresses some of the worst excesses of the food system even as it largely avoids state intervention and reform of global institutions, and (2) provides greater choice to consumers even as it makes choice into a burden.

\section{References}

Bain, Carmen. 2007. Reconciling Competing Values for 'Corporate Social Responsibility:' EurepGAP Standards and the Chilean Export Fruit Sector. East Lansing: Michigan State University $\mathrm{PhD}$ dissertation.

Brown, Stephen A. 1997. Revolution at the checkout counter. Cambridge, Mass.: Distributed by Harvard University Press.

Busch, Lawrence. 2007. "Performing the economy, performing science: from neoclassical to supply chain models in the agrifood sector." Economy and Society 36:439-468.

Busch, Lawrence, Deepa Thiagarajan, Maki Hatanaka, Carmen Bain, Luis G. Flores, and Mark Frahm. 2005. The Relationship Of Third-Party Certification (TPC) To Sanitary/Phytosanitary (SPS) Measures and the International Agri-Food Trade: Final Report. Washington, DC: Development Alternatives, Inc.

Caswell, Julie A., Maury E. Bredahl, and Neal H. Hooker. 1998. "How Quality Management Metasystems are Affecting the Food Industry." Review of Agricultural Economics 20:547-557.

Constant, Benjamin. 1988. Benjamin Constant: Political Writings. Cambridge: Cambridge University Press.

Corbett, L. C. 1905. Tomatoes. Washington, DC: USDA, Farmers' Bulletin No. 220.

Dries, Liesbeth, Thomas Reardon, and Johan F.M. Swinnen. 2004. "The Rapid Rise of Supermarkets in Central and Eastern Europe: Implications for the Agrifood Sector and Rural Development." Development Policy Review 22: 525-556.

Eyre, Charlotte. 2008. Global consumer conscience to boost fair-trade sales. Montpellier: Food Navigator. Date Accessed: April 9, http://www.foodnavigator.com/.

Friedman, Milton. 1962. Capitalism and Freedom. Chicago: University of Chicago Press.

Gereffi, Gary, Ronie Garcia-Johnson, and Erika Sasser. 2001. "The NGO-Industrial Complex." Foreign Relations 125:56-65.

GLOBAL G.A.P. 2008. Welcome to Globalgap. Cologne: Globalgap. Date Accessed: April 9, http://www.globalgap.org.

Goffman, Erving. 1993. "On Face-Work." Pp. 358-363 in Social Theory: The Multicultural and Classic Readings, edited by Charles Lemert. Boulder, CO: Westview Press.

Hatanaka, Maki. 2006. Producing Sustainable Shrimp: Third Party Certification in the Global South. East Lansing: Michigan State University PhD dissertation.

Hayek, Friedrich A. 1973. Rules and Order. London: Routledge and Kegan Paul. 
—. 1976. The Mirage of Social Justice. Chicago: University of Chicago Press.

—. 1979. The Political Order of a Free People. Chicago: University Of Chicago Press. Idhe, Don. 1979. Technics and Praxis. Dordrecht: D. Reidel.

- 1990. Technology and the Lifeworld: From Garden to Earth. Bloomington: Indiana University Press.

Latour, Bruno. 1987. Science in Action: How to Follow Scientists and Engineers Through Society. Milton Keynes, England: Open University Press.

Mead, George Herbert. 1962. Mind, Self, and Society from the Standpoint of a Social Behaviorist. Chicago: University of Chicago Press.

Reardon, Thomas, C. Peter Timmer, Christopher B. Barrett, and Julio Berdegue. 2003. "The Rise of Supermarkets in Africa, Asia, and Latin America." American Journal of Agricultural Economics 85:1140-1146.

Samuels, Warren J. 2004. "Markets and Their Social Construction." Social Research 71:357-370.

Scott, James C. 1998. Seeing Like a State: How Certain Schemes to Improve the Human Condition Have Failed. New Haven, CT: Yale University Press.

Stanziani, Alessandro. 2005. Histoire de la Qualité Alimentaire. Paris: Seuil.

Thompson, E. P. 1963. The Making of the English Working Class. New York: Vintage Books.

—. 1971. "The Moral Economy of the English Crowd in the Eighteenth Century." Past and Present 50:76-136.

Weatherspoon, Dave D., and Thomas Reardon. 2003. "The Rise of Supermarkets in Africa: Implications for Agrifood Systems and the Rural Poor." Development Policy Review 21:1-17.

Wootliff, Jonathan, and Christopher Deri. 2001. "NGOs: The New Super Brands." Corporate Reputation Review 4:157-164. 